\title{
Circadian Photoreception in Vertebrates
}

\author{
S. Doyle AND M. MenaKeR \\ Department of Biology, University of Virginia, Charlottesville, Virginia 22936
}

\begin{abstract}
To be adaptively useful, internal circadian clocks must be entrained (synchronized) to daily rhythms in the external world. The entraining process adjusts the period of the internal clock to 24 hours and its phase to a value that determines the organism's temporal niche (e.g., diurnal and nocturnal). For most vertebrates, the dominant environmental synchronizer is light. All vertebrates employ specialized photoreceptor cells to perceive synchronizing light signals, but mammals and nonmammalian vertebrates do this differently. Mammals concentrate circadian photoreceptors in the retina, employing rods, cones, and a subset of retinal ganglion cells that are directly photosensitive and contain an unusual photopigment (melanopsin). Nonmammalian vertebrates use photoreceptors located deep in the brain and in the pineal gland as well as others in the retina. Such photoreceptor extravagance is difficult to explain. It seems likely that the different photoreceptor classes in this elaborate sensory system may have specialized roles in entrainment. There is some evidence that this is in fact the case. Furthermore, this nonvisual "circadian" photoreceptive system also controls acute behavioral responses to light (masking), pupillary constriction, and photoperiodic regulation of reproductive state. We review some of the early work on birds and describe new findings that indicate specific roles for retinal rods, cones, and photosensitive retinal ganglion cells in mammals.
\end{abstract}

\section{INTRODUCTION}

In the Discussion following Tony Lees' paper (Lees 1961) from the 25th Cold Spring Harbor Symposium held in 1960, Donald Kennedy made a characteristically prescient remark. Lees' paper was in part about photoperiodism in aphids. Using fine-gauge metal tubes as light guides applied to various parts of the bodies of these tiny insects, Lees had shown that the photoreceptors involved were not in the eyes but were most probably in the brain itself. Kennedy, who himself had worked on "primitive" photoreceptors in invertebrates, said: "These very beautiful results, I think, call attention to the important business of specifying the light reception involved in photoperiodic control - or light entrainment of rhythms... . One might, in the light of such evidence, be cautious about assuming that photoperiodic control is mediated by "obvious' photoreceptor structures in any given case." In the intervening 47 years, the study of photoreception by "nonobvious" structures in vertebrates has become a cottage industry.

The mechanisms by means of which the vertebrate eye and associated brain areas form visual images have long been the focus of persistent and highly successful research efforts. The very success in this understanding of image formation has led, until recently, to a lack of appreciation of other mechanisms for light perception possessed even by vertebrates with elaborate image-forming eyes. Evidence for the existence of such mechanisms has been accumulating slowly for some time. As early as 1911 , von Frisch showed pigment color changes in the skin of minnows that persisted after removal of the eyes and pineal gland (von Frisch 1911). Scharrer (1928) subsequently demonstrated that blinded fish could be trained to associate feeding with a light stimulus. In 1935, Benoit and colleagues published the first in a series of papers in which they clearly showed that ducks whose eyes had been surgically removed could still perceive day length: Their gonads grew dramatically when they were kept in long (but not short) days. Although these observations were surprising and implied the existence of unidentified photoreceptors in unknown locations, they were not vigorously pursued, in part, because they were isolated cases with no common functional thread to connect them. One candidate structure, the pineal/parietal complex in amphibians and reptiles, had long been assumed to be photoreceptive (Leydig 1890), but interest in studying it was somewhat dampened by inability to identify a clear function despite many attempts.

In the mid-1960s, my students and I discovered serendipitously that house sparrows, whose eyes had been removed for other reasons, could still synchronize their activity rhythms to light cycles. Subsequent work by us and other investigators has established that such "extraretinal" entrainment is a property of the circadian systems of all nonmammalian vertebrates and depends on photoreceptors in several brain areas. In mammals, there are no "extraretinal" photoreceptors; however, circadian entrainment is accomplished in part by a population of nonvisual photosensitive retinal ganglion cells. Circadian entrainment thus finally provided the functional connection among several diverse nonvisual photoreceptive systems that was necessary to stimulated intense research. As work has progressed on these systems, other functions have been uncovered. In the future, it will be of particular interest to explore, especially in mammals, how the visual and nonvisual photoreceptive systems, which operate under very different physiological constraints, interact with each other in the regulation of these several functions. We have briefly reviewed here some of the early work in birds and related it to ongoing experiments on nonvisual functions of the mammalian retina. 


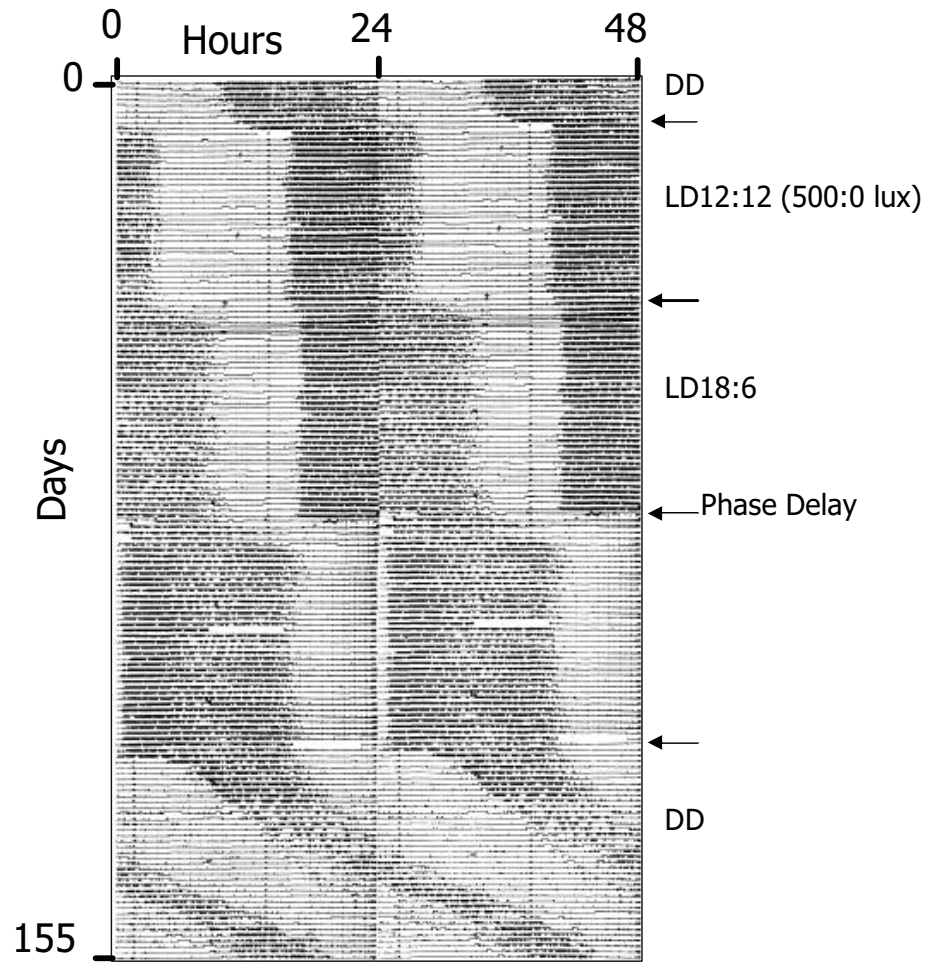

Figure 1. Perch-hopping activity of a blinded sparrow, maintained as indicated to the right of the record in constant darkness (DD), a 12-hour light:12-hour dark cycle (LD12:12), and an 18hour light:6-hour dark cycle (LD18:6). On the day marked "phase shift," the LD16:8 cycle was delayed by 9.5 hours. The record is double plotted so that the righthand side of the record is displaced upward 1 day and each horizontal line equals 48 hours. (Reprinted from Menaker 1968a [National Academy of Sciences].)

\section{HOUSE SPARROWS POSSESS EXTRARETINAL PHOTORECEPTORS COUPLED TO THE CIRCADIAN CLOCK CONTROLLING LOCOMOTOR ACTIVITY}

We measured circadian rhythms of locomotor activity in house sparrows by continuously recording perch-hopping behavior (Menaker 1968a). Figure 1 shows a representative record from a bilaterally enucleated sparrow. For the first several days of the record, the sparrow was maintained in constant darkness and displayed a locomotor activity rhythm with a free-running period slightly longer than 24 hours, as is common in sighted sparrows. On day 7 of the record, a 12-hour light:12-hour dark cycle of 500 lux from white fluorescent light bulbs was imposed. The blinded sparrow readily entrained to this light:dark cycle and also responded normally to subsequent manipulations of the light:dark cycle (i.e., increasing the photoperiod to light:dark $16: 8$ on day 40 and delaying the light:dark cycle by 9.5 hours on day 79). When returned to constant darkness on day 117, the bird began to free-run once again. These experiments strongly suggested that house sparrows possessed extraretinal photoreceptor(s) mediating circadian entrainment to light. Further experiments ruled out the possibility that the birds were responding to another rhythmic feature in their environment, such as heat, noise, or electrical fields (Menaker 1968a). We also found the extraretinal photoreceptor to be surprisingly sensitive. Approximately one half of blinded sparrows entrained to a 12-hour light:12-hour dark cycle in which the light source was a small electroluminescent panel producing green light of 0.1 lux (Fig. 2) (Menaker 1968a).

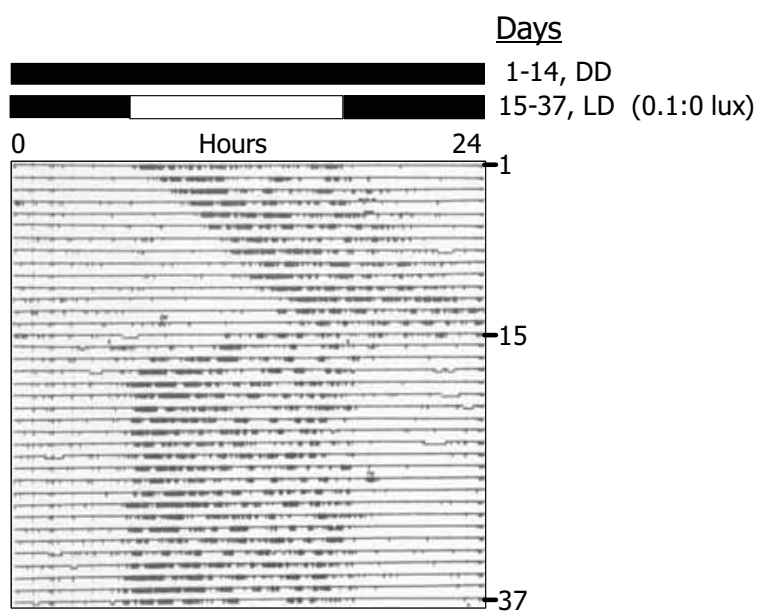

Figure 2. Perch-hopping record of a blinded sparrow. During the first 14 days of the record, the bird was maintained in constant darkness (DD) and free-ran with a period of approximately 25 hours. On day 15, the bird was exposed to a 12-hour light:12hour dark cycle (LD), with 0.1 lux green light during the light phase. After 2-3 days of transients, the sparrow entrained to this regime. (Reprinted from Menaker 1968a [National Academy of Sciences].)

\section{THE EXTRARETINAL PHOTORECEPTOR OF SPARROWS IS LOCATED WITHIN THE BRAIN}

Early work by Benoit (1935) suggested that light directed to the hypothalamus affected photoperiodic testis growth in blinded ducks. These data and the relative 


\section{CIRCADIAN PHOTORECEPTION IN VERTEBRATES}

transparency of the avian skull suggested to us that the extraretinal photoreceptor might be localized within the brain. To test this hypothesis, we conducted an experiment in which six enucleated sparrows were exposed to a 12-hour light:12-hour dark cycle of 0.02 lux, just below the threshold for entrainment (Fig. 3) (Menaker 1968b). We then plucked feathers from an approximately halfinch-diameter area on the birds' back. This treatment had no effect on activity rhythms, and the birds continued to free-run through the dim light:dark cycle. We next plucked feathers from a similarly sized area on the birds' heads and found that after this manipulation, the activity rhythms of all of the sparrows rapidly entrained to the light:dark cycle. About 4 weeks later, the feathers regrew and the bird began to drift out of entrainment. When these new feathers were plucked, the bird entrained again. After India ink was injected under the skin above the skull to decrease the effective light intensity reaching underlying tissues, the birds free-ran once more. Finally, when the ink deposit was scraped away, the birds reentrained to the

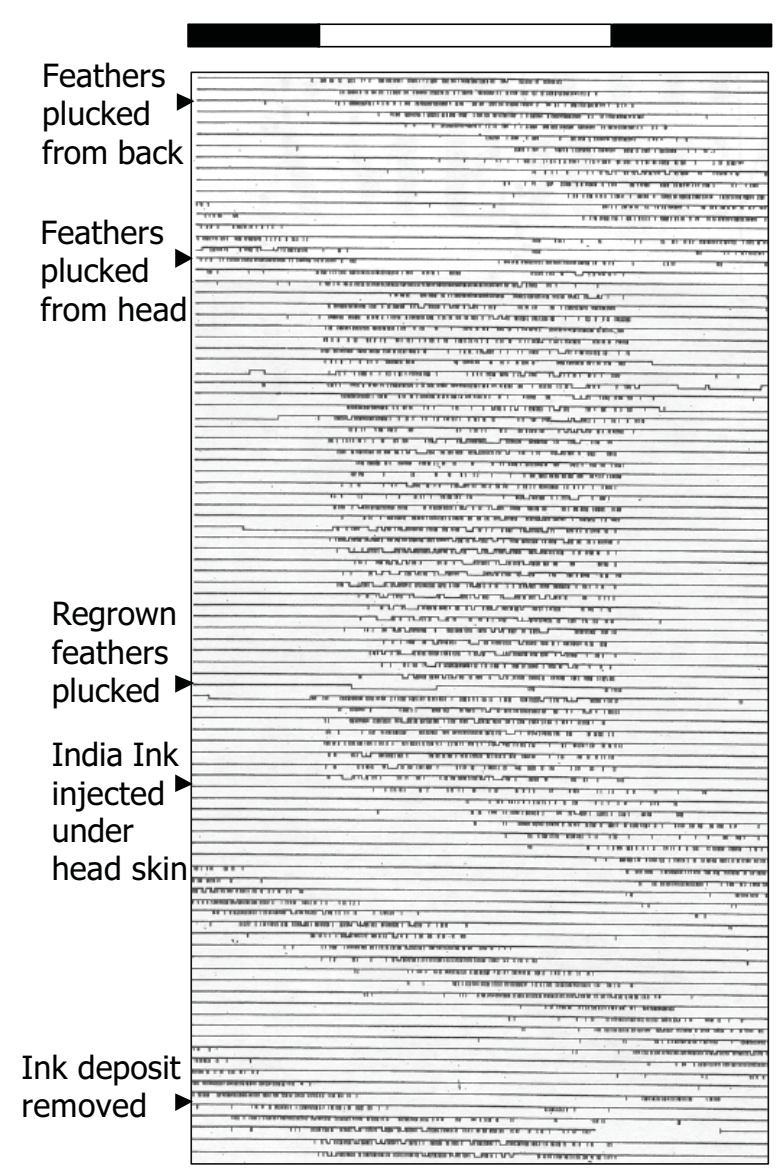

Figure 3. Perch-hopping rhythm of a blinded sparrow, maintained in a 12-hour light:12-hour dark cycle (0.02 lux green light during the light phase, as indicated at the top of the figure) for the duration of the record and, on the days indicated by the arrowheads, subjected to the manipulations described at the left of the record. (Reprinted from Menaker 1968b [National Academy of Sciences].) light:dark cycle. Pinealectomy had no effect on the entrainment of blinded sparrows if subjected to the above manipulations (Menaker 1968b). These experiments demonstrate that manipulation of the light intensity reaching the brain of blinded sparrows affects the ability of the animals to entrain to light cycles and indicate that the extraretinal photoreceptor(s) are located within the brain. The discovery of extraretinal brain photoreceptors raised the question of whether the eyes, when present, are involved at all in photoperiodism, entrainment, and other circadian responses to light such as changes in free-running period in response to constant light and the effect of constant light in producing arrhythmicity. Interestingly, the role of the eyes and the extraretinal photoreceptors was found to vary for each of these responses.

\section{The Eyes Contribute to Circadian Entrainment}

As described above, approximately $50 \%$ of blinded sparrows entrained to a light:dark cycles of an intensity of 0.1 lux; however, all sighted birds entrain to light of this intensity. Therefore, the eyes, although not necessary for circadian entrainment, do appear to contribute light information for entrainment when they are present. The suspected contribution of both the eyes and extraretinal photoreceptors to circadian entrainment was conclusively demonstrated by McMillan et al. (1975c), who exposed intact birds to light:dark cycles of very dim intensity $(0.03$ lux). Under these conditions, $25 \%$ of the birds free-ran, suggesting that this intensity is close to threshold for entrainment in intact birds. McMillan then either plucked head feathers from free-running birds or injected carbon black between the skin and skull of entrained birds to either increase or decrease, respectively, the amount of light reaching brain photoreceptors. All plucked birds subsequently entrained and nearly half of the carbonblack-injected birds began to free-run. When blinded, birds that had remained entrained after carbon black injection began to free-run. The fact that photosensitivity for entrainment was greater in intact birds than in blinded or injected birds demonstrated that both the extraretinal photoreceptors and the eyes contribute to entrainment in intact birds.

\section{The Eyes Contribute to Free-running Period Changes in Constant Light}

In many animals, constant light has dramatic effects on the circadian clock, altering period length, and above certain thresholds, producing arrhythmicity. In sparrows, the free-running period $(\tau)$ shortens as light intensity is increased and lengthens as it is reduced. Like the situation in intact birds, blinded sparrows exhibit shortening of the free-running period of activity in response to increasing intensities of constant light (Fig. 4) (Menaker 1968a). Treatments altering the level of light input from the eyes or the extraretinal photoreceptors in intact and blinded birds affect the free-running period in the expected directions, showing that both the eyes and the extraretinal photoreceptors mediate the effects of constant light on the 


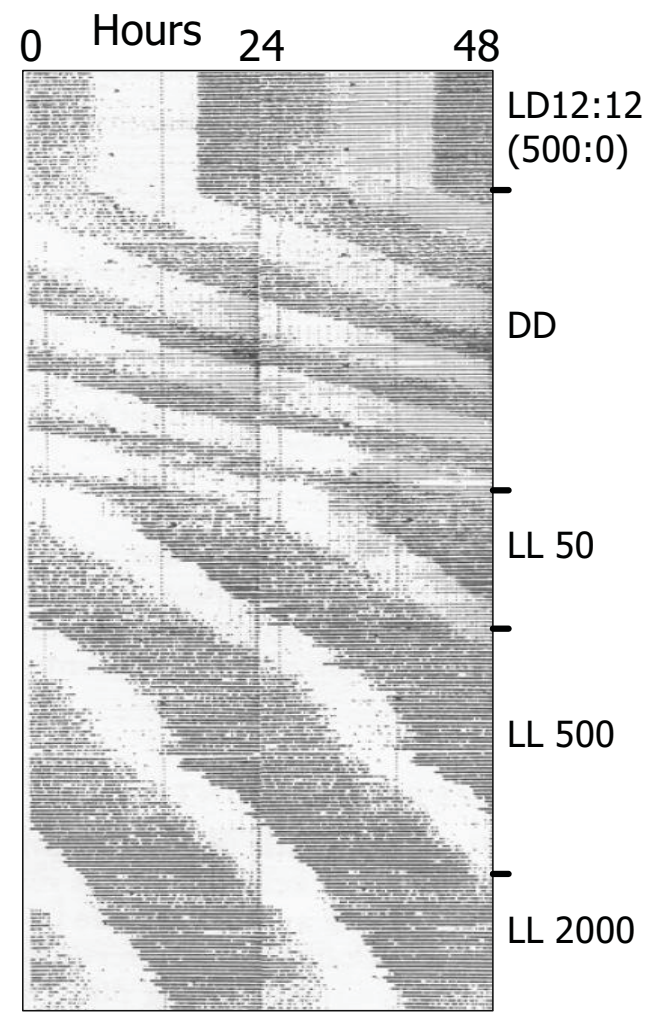

Figure 4. Perch-hopping record of a blinded sparrow, maintained in LD12:12 (500 lux), DD, and then exposed to constant light (LL) of three intensities as indicated at the right of the record. Note the large change in free-running period and the increase in total activity time upon transfer to from DD to LL, and smaller period changes as the intensity of LL is increased. In LL of 2000 lux, feathers were plucked from the bird's head, raising the effective intensity to 20,000 lux (feathers attenuate light intensity by a factor of 10). Note that the bird did not become arrhythmic. (Reprinted from Menaker 1968a [National Academy of Sciences].)

free-running period. Blinding and hooding to decrease the amount of light reaching the brain both lengthen $\tau$, whereas head feather plucking or removal of the hood shortens $\tau$ (McMillan et al. 1975b).

\section{The Eyes Are Necessary for LL-induced Arrhythmicity}

In intact house sparrows, the intensity of constant light required to produce arrhythmicity is surprisingly low and lies between 10 and 100 lux (Menaker 1977). In constant dim light (1.0 lux), rhythmic intact birds will become arrhythmic when the light intensity reaching the brain photoreceptors is increased by plucking head feathers. Rhythmicity can then be restored with carbon black injection (McMillan et al. 1975a). However, blind birds will not become arrhythmic in constant light, even at effective intensities of 20,000 lux (Fig. 4). These results indicate that even though extraretinal photoreceptors contribute to the production of LL-induced arrhythmicity, the eyes are required for this effect of light on the clock.

\section{The Eyes Are Not Involved in Photoperiodic Photoreception}

In the wild, male sparrows undergo a dramatic annual cycle of gonadal growth. During spring, when the photoperiod increases to 14 hours or more of light per day, testis weight increases by approximately 500-fold (Fig. 5A) (Menaker 1971). We examined photoperiodic photoreception in the sparrow with respect to the role of the eyes. Both intact and blinded birds showed identical reproductive responses in terms of testis weight, histology, and rates of gonadal growth when exposed to long photoperiods (Menaker and Keatts 1968; Underwood and Menaker 1970). Furthermore, the threshold for the photoperiodic response was more than two orders of magnitude higher than the threshold for vision (Menaker 1977), suggesting that the eyes had little or no role in photoperiodic responses to light. A key experiment, shown in Figure $5 \mathrm{~B}$, was conducted in which sparrows with intact eyes were exposed to 16-hour light:8-hour dark cycles of intensity close to threshold for the photoperiodic reproductive response (Menaker et al. 1970; Menaker 1971). Head feathers were plucked from one group of birds to increase the amount of light reaching the brain, whereas India ink was injected beneath the head skin of another group of birds to decrease the light intensity reaching the brain. The testes of the plucked birds increased in size; however, despite the fact that their eyes were exposed to long days, those of the India-ink-injected group showed no increase compared to a control group of sparrows with small testes that had been maintained on short days. These results demonstrated that the eyes are not involved in photoperiodic photoreception.

\section{MAMMALIAN PHOTOENTRAINMENT}

In contrast to nonmammalian vertebrates, in which extraretinal photoreceptors are widespread, in mammals, circadian entrainment and other nonvisual light responses are mediated exclusively by the eyes (Nelson and Zucker 1981). Although it has been clear for some time that mammalian nonvisual photoreception was based in the retina, the photoreceptors involved have only recently been identified. In the early 1990s, Foster and colleagues examined circadian photoresponses in $r d / r d$ mice with severe degeneration of the outer retina. Surprisingly, these mice, lacking all rods and most cones, showed circadian phaseshifting responses to light that were indistinguishable in sensitivity from those of wild-type control mice (Foster et al. 1991). Similar results were later obtained using mice with more complete lesions of the outer retina, $\mathrm{rdta} ; \mathrm{cl}$ (Freedman et al. 1999). The insensitivity of circadian photoreception to loss of rod and cone function implicated a novel nonrod, noncone photoreceptor. These photoreceptors were recently identified as a small subset of intrinsically photosensitive retinal ganglion cells (ipRGCs), containing the photopigment melanopsin (OPN4; Provencio et al. 1998, 2000; Berson et al. 2002; Hattar et al. 2002). "Triple-knockout" mice lacking rods, 

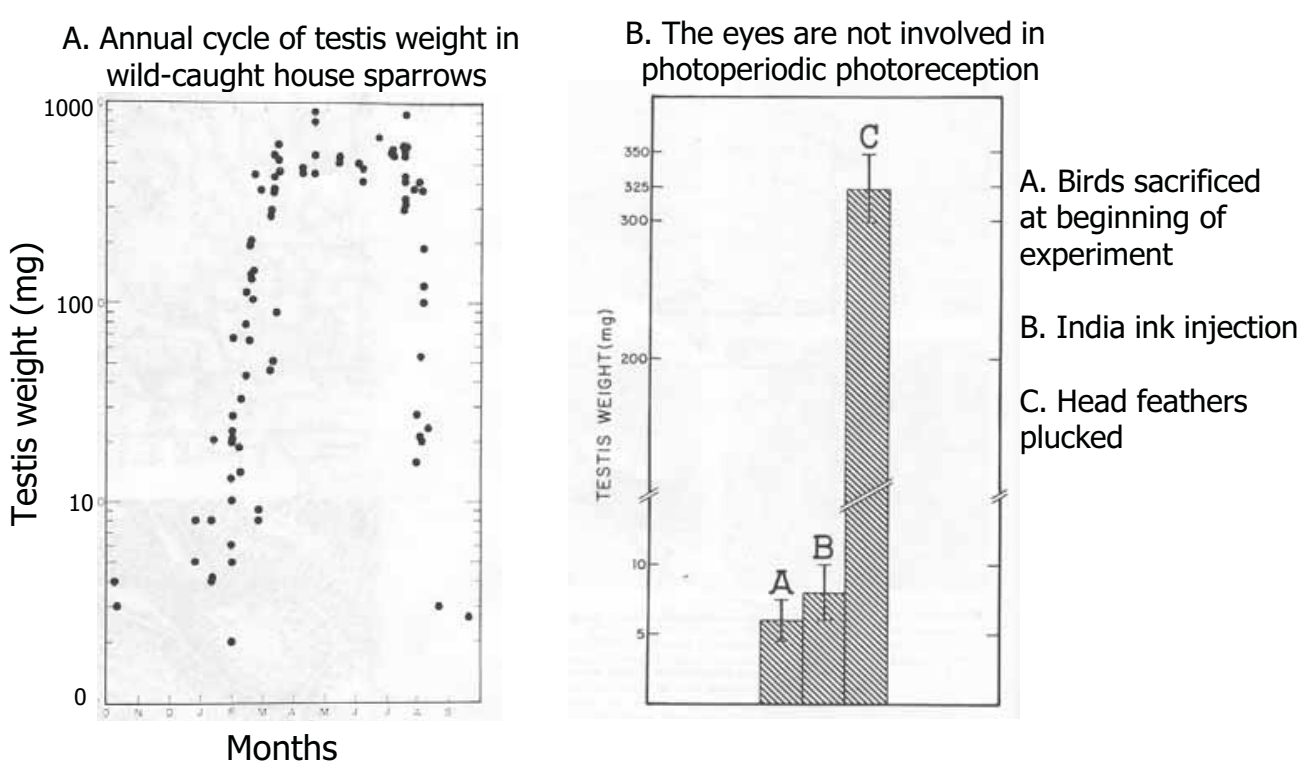

Figure 5. (A) Testis weight measured from individual wild-caught sparrows over the course of 1 year. Each point represents combined weight of both testes from a single bird. $(B)$ Testis weight from intact sparrows exposed to a long-day photoperiod and subjected to manipulations (indicated at the right of the graph) to either decrease or increase the amount of light reaching the brain. (Reprinted from Menaker 1971 [National Academy of Sciences].)

cones, and melanopsin lose all circadian responses to light (Hattar et al. 2003; Panda et al. 2003). In melanopsin knockout mice, ipRGCs lose their photosensitivity (Hattar et al. 2002), yet circadian photoresponses, although attenuated, are not completely lost (Panda et al. 2002; Ruby et al. 2002). This suggests that rods, cones, and melanopsin-based photoreceptors all participate in circadian photoreception and raises questions regarding the specific roles of these photoreceptors and their possible interactions.

\section{INTERACTION BETWEEN RODS AND IPRGCs}

We have recently examined the effect of loss of RPE65, a key enzyme for recycling the 11-cis-retinaldehyde chromophore of rods and cones, on circadian photoreception in mice. Rpe $65^{-/-}$mice lose cone function and retain only a small amount of rod function (Seeliger et al. 2001; Wenzel et al. 2007). In contrast to the intact circadian photoresponses reported in mouse models with more complete rod and cone dysfunction, we found that circadian phase-shifting responses in Rpe $65^{-1-}$ mice were greatly attenuated (Fig. 6) (Doyle et al. 2006). These results indicated that melanopsin cells as well as rods and cones had been affected by RPE65 loss and initially suggested that melanopsin might use RPE65 to recycle its chromophore. However, we subsequently generated Rpe $65^{-/-}$mice carrying the $r d t a$ transgene (McCall et al. 1996), which produces rapid and complete ablation of rod photoreceptors. Photoreception in these mice is therefore limited to ipRGCs. Surprisingly, circadian entrainment and phase-shifting responses were restored

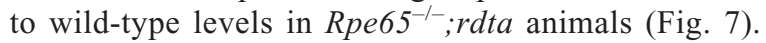
This restoration of circadian photosensitivity demonstrated that melanopsin can use a chromophore regeneration pathway independent of that used by visual photoreceptors. It also revealed an intriguing interaction between the rod and melanopsin systems, suggesting that in the Rpe $65^{-1-}$ retina, rods were somehow inhibiting ipRGC function.

\section{ROD PATHWAYS AND CONTROL OF TEMPORAL NICHE}

We eliminated melanopsin from $R p e 65^{-1-}$ retinas by generating double-knockout $R p e 65^{-1-} ; \mathrm{Opn}^{H^{--}}$mice. When maintained in a 12-hour light:12-hour dark cycle, we found that $80 \%$ of these mice displayed a very striking diurnal activity phenotype (Fig. 8); the remaining 20\% free-ran through the light:dark cycle. Furthermore, after release into constant darkness, the activity onset of "diurnal" mice free-ran from the time of lights-on, indicating that their circadian activity rhythms were not simply masked but were entrained to the diurnal phase. The loss of the ability of Rpe $65^{-/} ; \mathrm{Opn4^{-/- }}$ mice to maintain normal photoentrainment indicated that melanopsin provides the majority of the photic input to the circadian system of Rpe $65^{-/-}$mice. However, the very striking diurnal phenotype also suggests that retinal input may have a greater role in determining temporal niche than previously believed. Because loss of RPE65 has been shown to eliminate cone function (Seeliger et al. 2001; Znoiko et al. 2005; Wenzel et al. 2007), rod pathways alone must medi- 


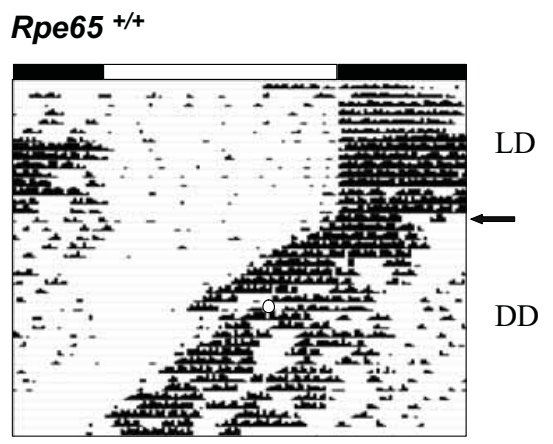

Rpe65 +/-

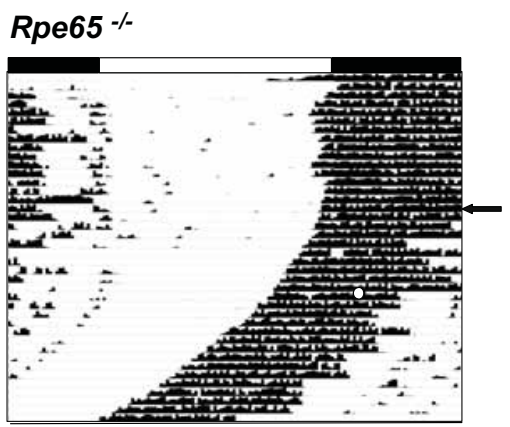

Figure 6. Representative actograms from an Rpe65 wild-type, heterozygote, and homozygous knockout. Mice were maintained in a 12-hour light:12-hour dark cycle (LD), indicated by black and white bars above each record and, on the day indicated by the arrow, were released into constant darkness (DD). After 10-12 days in DD, the animals were given a 15-minute light pulse $(515 \mathrm{~nm}, 0.1$ $\mu \mathrm{W} / \mathrm{cm}^{2}$ ) at circadian time (CT) 16 (open circles). (Reprinted from Doyle et al. 2006 [@National Academy of Sciences].)

\section{Rpe65 \%}

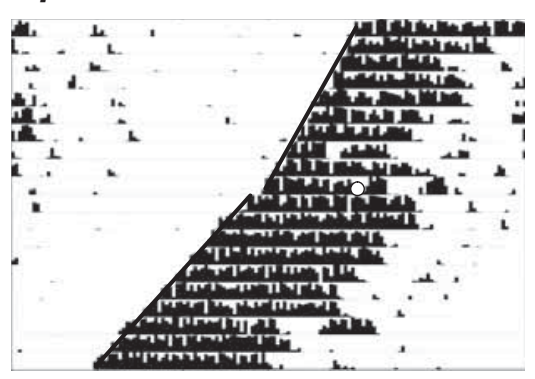

Rpe65\%; rdta

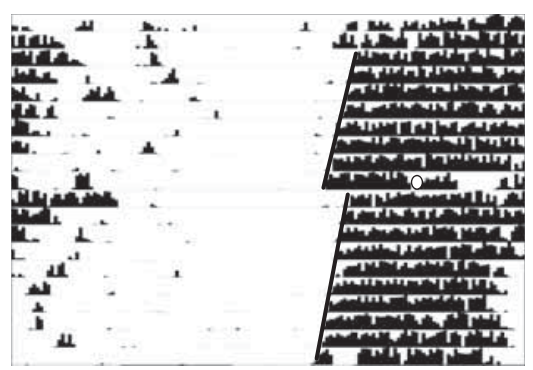

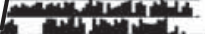

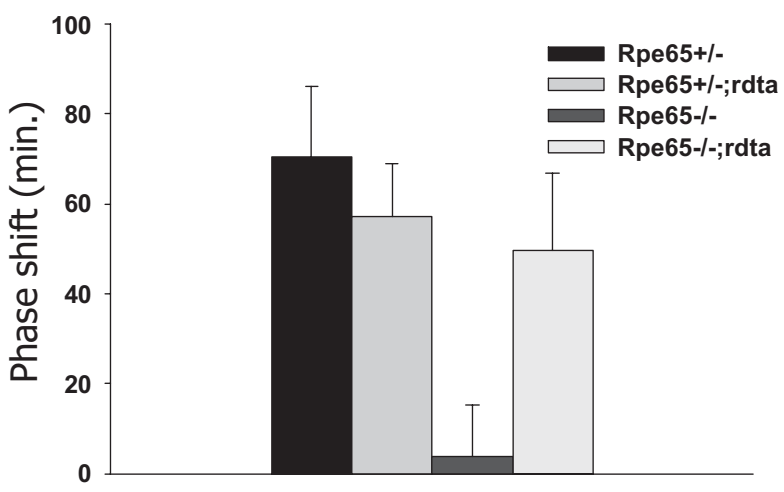

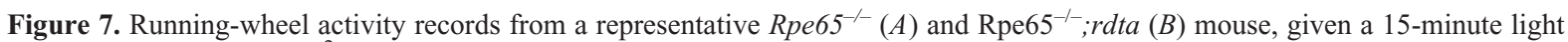
pulse $\left(515 \mathrm{~nm}, 0.1 \mu \mathrm{W} / \mathrm{cm}^{2}\right)$ at CT 16 after free-running in constant darkness. Best-fit lines are drawn through activity onsets on the days before and after the light pulse (open circles). (C) Histogram showing mean phase shift ( \pm S.E.M.). (Reprinted from Doyle et al. 2006 [C National Academy of Sciences].) 


\section{CIRCADIAN PHOTORECEPTION IN VERTEBRATES}
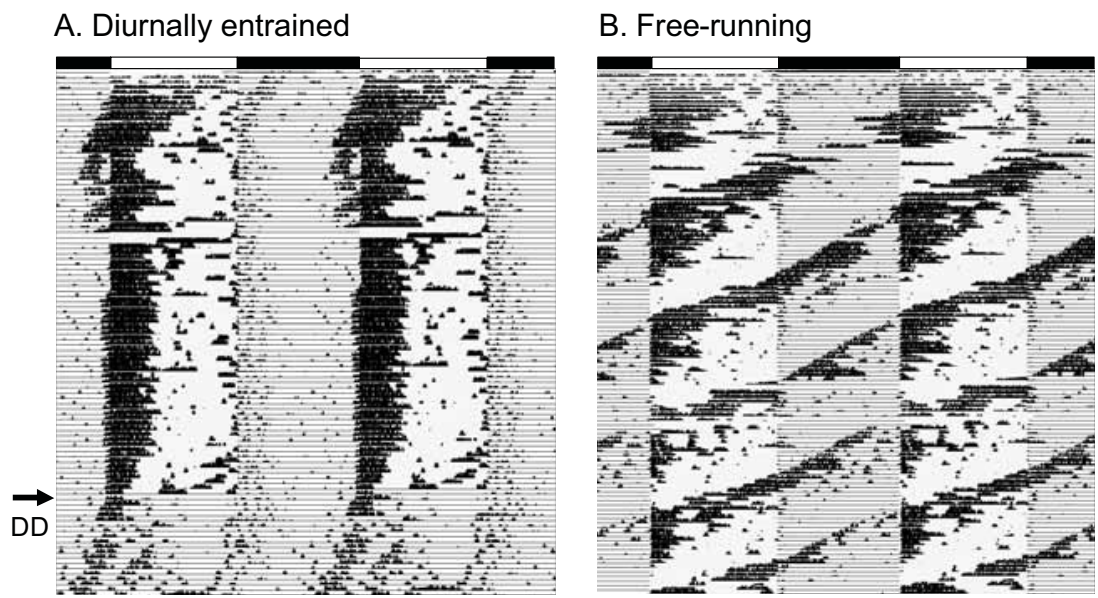

Figure 8. Double-plotted wheel-running records of a diurnally entrained $(A)$ and a free-running $(B) R p e 65^{-1-} ; O p n 4^{-1-}$ mouse maintained in a 12-hour light:12-hour dark cycle. The light:dark cycle is indicated by black and white bars at the top of each record. The arrow in $A$ indicates the day of release into constant darkness. (Reprinted from Doyle et al. 2006 [CNational Academy of Sciences].)

ate the temporal niche switching of $\mathrm{Rpe}^{\mathrm{S}} 65^{-1-} ; \mathrm{Opn} 4^{-1-}$ mice. We are currently testing the hypothesis that dim light, below the sensitivity range of cones and melanopsin, can produce a similar phenotype in wild-type mice.

\section{CONCLUSIONS}

Synchronization of circadian clocks with the external environment is essential for their adaptive function. Photoreception provides a critical link between the environment and circadian clocks. However, circadian photoreceptors must accomplish a photoreceptive task, irradiance detection, which is qualitatively different from the fine spatial and temporal resolution carried out by the photoreceptors involved in image formation. This distinction is emphasized by the universality of the separation of visual and nonvisual photoreceptors. Specialized photoreceptors that convey information about environmental light conditions to the circadian system occur widely in invertebrates and in all five vertebrate classes.

A key question in our investigation of the circadian and photoperiodic responses to light in the house sparrow has been: What are the relative contributions of the eyes and the extraretinal photoreceptors? We have approached this question by comparing the similarities and differences between blinded and intact birds. Photoperiodic stimulation of testicular growth is mediated exclusively by extraretinal photoreceptors; the eyes do not have any role in this response. However, the eyes do participate in three circadian responses to light: entrainment, period change in LL, and arrhythmicity in LL. This last response cannot be produced in the absence of the eyes and is the only one of the above four "nonvisual" light responses that requires their input. Thus, four different responses to light involve three different patterns of interactions between the retinal and extraretinal inputs.

Experiments examining the roles of retinal and extraretinal photoreceptors in circadian photoreception have also been undertaken in lizards and have yielded results that are not only different from those of sparrows, but also vary among lizard species (Underwood and Menaker 1976). These interactions are likely to be quite different in different species and will most certainly depend on the specific photic niche occupied by the animal. The recent discovery of melanopsin has added a new and interesting level of complexity to the study of these interactions. Although it has a central role in mammalian circadian photoreception, its photoreceptive role in nonmammalian vertebrates has not been investigated. In nonmammalian vertebrates, melanopsin expression has been reported in subsets of horizontal, amacrine, and/or ganglion cells, depending on the species (Provencio et al. 1998; Bellingham et al. 2002; Drivenes et al. 2003; Jenkins et al. 2003; Chaurasia et al. 2005; Tomonari et al. 2007). Although the function(s) of mammalian melanopsin cells and their interactions with retinal rods and cones are an area of active research, it is virtually unexplored in nonmammalian vertebrates.

The existence of brain photoreceptors regulating photoperiodism and circadian entrainment has been described in many invertebrate groups and in all classes of vertebrates, with the exception of mammals (Shand and Foster 1999). In vertebrates, neurons immunoreactive for various opsins have been localized to the walls of brain ventricles in the hypothalamus and septum (Vigh et al. 2002). On the basis of this anatomical evidence, these cells have been assumed to be deep-brain photoreceptors. However, there has only been one report linking a specific population of putative deep-brain photoreceptors, in the hypothalamus of the ruin lizard Podarcis sicula, to circadian function (Pasqualetti et al. 2003). With the exception of this one case, we do not even know whether the opsins of these putative photoreceptor cells form functional photopigments, much less what type of phototransduction cascade might be involved. The neural and/or humoral inputs and outputs of these cells are also completely unexplored. 
Mammals lack extraretinal photoreception, and the photoreceptors subserving visual and nonvisual functions coexist within the eye. The respective roles of the three photoreceptor classes that mediate nonvisual light responses in mammals - rods, cones, and melanopsincontaining ipRGCs - have been addressed to some extent by comparing the phenotypes of mice with degeneration or dysfunction of rods and/or cones to those of melanopsin knockout mice. As in nonmammalian vertebrates, there is redundancy between different photoreceptor types, and the role of the different photoreceptor classes appears to vary depending on the nonvisual response. For example, mice lacking both rod- and conebased photoreception are able to phase shift and lengthen the free-running period in constant light with virtually unattenuated sensitivity when compared to wild-type mice (Foster et al. 1991; Argamaso et al. 1995; Freedman et al. 1999; Mrosovsky 2003; Panda et al. 2003). In melanopsin knockout mice, these responses are not eliminated but are substantially impaired (Panda et al. 2002; Ruby et al. 2002), suggesting that the primary photoreceptive input for circadian light responses comes from melanopsin. On the other hand, another nonvisual light response, the pupillary light reflex, appears to rely heavily on rod/cone input (Lucas et al. 2001). A caveat to the interpretation of these data is the question of whether developmental compensation occurs as a result of rod, cone, or melanopsin loss. This issue could be addressed through the use of conditional knockouts.

In addition to their intrinsic photoresponses, ipRGCs are activated by light signals originating in the rods and cones (Dacey et al. 2005; Perez-Leon et al. 2006; Wong et al. 2007). Rods and cones are thus capable of interacting with ipRGCs or providing separate input for nonvisual responses through a small number of conventional retinal ganglion cells that project to nonvisual centers in the brain (Gooley et al. 2003; Morin et al. 2003; Hattar et al. 2006). The pathways within the retina through which light information from rods and cones reach ipRGCs have just begun to be characterized. Recent studies indicate that rod and cone signals travel through both ON and OFF bipolar and amacrine pathways (Belenky et al. 2003; Viney et al. 2007; Wong et al. 2007). The effects of rod and cone input on nonvisual light responses are therefore likely to be complex and may differ in diurnal mammals with cone-dominated retinas. Although future studies using rod- and cone-specific knockouts will be necessary for a complete understanding of the contribution of rods versus cones to nonvisual physiology, recent behavioral studies suggest that manipulation of rod and cone pathways can have significant effects on entrainment. Abnormal phase angles of entrainment have been reported in $T R \beta_{2}{ }^{-1-}$ mice lacking mid-wavelength cones (Dkhissi-Benyahya et al. 2007), and in Rpe65 $5^{-1-}$ mice (Doyle et al. 2006). The dramatic reversal of entrainment

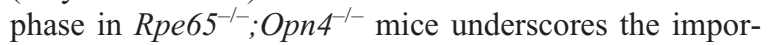
tance of fully understanding these pathways.

The multiple extraretinal photoreceptors of nonmammalian vertebrates are often contained within tissues that are themselves circadian oscillators, e.g., the pineal gland of lamprey, birds, and lizards and the parietal eye of lizards (Zimmerman and Menaker 1979; Underwood 1990; Morita et al. 1992; Tosini and Menaker 1998). In zebra fish, peripheral oscillators in many organs and tissues are directly entrainable by light (Whitmore et al. 2000), a situation similar to that of Drosophila melanogaster, in which clock tissues all over the body use the flavin-based photoreceptor crypotochrome (Plautz et al. 1997; Emery et al. 2000). However, mammals lack extraretinal photoreceptors, with the possible exception of the neonatal pineal (Torres and Lytle 1989; Tosini et al. 2000). One attractive explanation for this difference in organization is the "nocturnal bottleneck" hypothesis, according to which the selective pressure for the shift from broadly distributed circadian photoreceptors to photoreceptors concentrated in the retina was the result of the enforced nocturnality of primitive mammals (Menaker et al. 1997). This hypothesis stems from the broader idea that the photic niche has a predominant role in shaping the circadian systems of vertebrates. The multiple extraretinal photoreceptors of nonmammalian vertebrates might therefore be necessary because they are each tuned to respond to different aspects of the animal's largely diurnal photic environment and/or to provide information directly to their closely associated oscillators. Indeed, "it may well be that the connection between light and the circadian system is a much more intimate one than is implied by the statement that light is the dominant natural entraining agent. In that case it might be possible to follow light into the heart of the mechanism" (Menaker et al. 1978). The strategy of following light input to the circadian system has been, and will in all probability continue to be, a particularly fruitful approach to understanding circadian organization (Gaston and Menaker 1968; Moore and Lenn 1972; Froehlich et al. 2002).

\section{ACKNOWLEDGMENTS}

The experimental work described in this paper has been supported over many years by grants from the National Science Foundation and the National Institutes of Health. The most recent work on mammalian retina has been supported by NIH grant MH56647.

\section{REFERENCES}

Argamaso S.M., Froehlich A.C., McCall M.A., Nevo E., Provencio I., and Foster R.G. 1995. Photopigments and circadian systems of vertebrates. Biophys. Chem. 56: 3 .

Belenky M.A., Smeraski C.A., Provencio I., Sollars P.J., and Pickard G.E. 2003. Melanopsin retinal ganglion cells receive bipolar and amacrine cell synapses. J. Comp. Neurol. 460: 380 .

Bellingham J., Whitmore D., Philp A.R., Wells D.J., and Foster R.G. 2002. Zebrafish melanopsin: Isolation, tissue localisation and phylogenetic position. Brain Res. Mol. Brain Res. 107: 128 .

Benoit J. 1935. Stimulation par la lumiere artificielle du developpement testiculaire chez des canards aveugles par enucleation des globes oculaire. C.R. Soc. Biol. 120: 136.

Berson D.M., Dunn F.A., and Takao M. 2002. Phototransduction by retinal ganglion cells that set the circadian clock. Science 295: 1070.

Chaurasia S.S., Rollag M.D., Jiang G., Hayes W.P., Haque R. Natesan A., Zatz M., Tosini G., Liu C., Korf H.W., Iuvone 


\section{CIRCADIAN PHOTORECEPTION IN VERTEBRATES}

P.M., and Provencio I. 2005. Molecular cloning, localization and circadian expression of chicken melanopsin (Opn4): Differential regulation of expression in pineal and retinal cell types. J. Neurochem. 92: 158.

Dacey D.M., Liao H.W., Peterson B.B., Robinson F.R., Smith V.C., Pokorny J., Yau K.W., and Gamlin P.D. 2005. Melanopsin-expressing ganglion cells in primate retina signal colour and irradiance and project to the LGN. Nature 433: 749.

Dkhissi-Benyahya O., Gronfier C., De Vanssay W., Flamant F., and Cooper H.M. 2007. Modeling the role of mid-wavelength cones in circadian responses to light. Neuron 53: 677.

Doyle S.E., Castrucci A.M., McCall M., Provencio I., and Menaker M. 2006. Nonvisual light responses in the rpe65 knockout mouse: Rod loss restores sensitivity to the melanopsin system. Proc. Natl. Acad. Sci. 103: 10432.

Drivenes O., Soviknes A.M., Ebbesson L.O., Fjose A., Seo H.C., and Helvik J.V. 2003. Isolation and characterization of two teleost melanopsin genes and their differential expression within the inner retina and brain. J. Comp. Neurol. 456: 84 .

Emery P., Stanewsky R., Helfrich-Forster C., Emery-Le M., Hall J.C., and Rosbash M. 2000. Drosophila cry is a deep brain circadian photoreceptor. Neuron 26: 493.

Foster R.G., Provencio I., Hudson D., Fiske S., De Grip W., and Menaker M. 1991. Circadian photoreception in the retinally degenerate mouse (rd/rd). J. Comp. Physiol. A 169: 39.

Freedman M.S., Lucas R.J., Soni B., von Schantz M., Munoz M., David-Gray Z., and Foster R. 1999. Regulation of mammalian circadian behavior by non-rod, non-cone, ocular photoreceptors. Science 284: 502.

Froehlich A.C., Liu Y., Loros J.J., and Dunlap J.C. 2002. White collar-1, a circadian blue light photoreceptor, binding to the frequency promoter. Science 297: 815 .

Gaston S. and Menaker M. 1968. Pineal function: The biological clock in the sparrow? Science 160: 1125.

Gooley J.J., Lu J., Fischer D., and Saper C.B. 2003. A broad role for melanopsin in nonvisual photoreception. J. Neurosci. 23: 7093.

Hattar S., Liao H.W., Takao M., Berson D.M., and Yau K.W. 2002. Melanopsin-containing retinal ganglion cells: Architecture, projections, and intrinsic photosensitivity. Science 295: 1065 .

Hattar S., Kumar M., Park A., Tong P., Tung J., Yau K.W., and Berson D.M. 2006. Central projections of melanopsinexpressing retinal ganglion cells in the mouse. J. Comp. Neurol. 497: 326.

Hattar S., Lucas R.J., Mrosovsky N., Thompson S., Douglas R.H., Hankins M.W., Lem J., Biel M., Hofmann F., Foster R.G., and Yau K.W. 2003. Melanopsin and rod-cone photoreceptive systems account for all major accessory visual functions in mice. Nature 424: 76.

Jenkins A., Munoz M., Tarttelin E.E., Bellingham J., Foster R.G., and Hankins M.W. 2003. VA opsin, melanopsin, and an inherent light response within retinal interneurons. Curr. Biol. 13: 1269

Lees A.D. 1961. Some aspects of animal photoperiodism. Cold Spring Harbor Symp. Quant. Biol. 25: 261.

Leydig F. 1890. Das parietalorgan der amphibien und reptilien. Abh. Senckenb. Ges. 16: 441.

Lucas R.J., Douglas R.H., and Foster R.G. 2001. Characterization of an ocular photopigment capable of driving pupillary constriction in mice. Nat. Neurosci. 4: 621.

McCall M.A., Gregg R.G., Merriman K., Goto Y., Peachey N.S., and Stanford L.R. 1996. Morphological and physiological consequences of the selective elimination of rod photoreceptors in transgenic mice. Exp. Eye Res. 63: 35.

McMillan J.P., Elliot J.A., and Menaker M. 1975a. On the role of eyes and brain photoreceptors in the sparrow: Arrhythmicity in constant light. J. Comp. Physiol. 102: 263.

. 1975b. On the role of eyes and brain photoreceptors in the sparrow: Aschoff's rule. J. Comp. Physiol. 102: 257.

McMillan J.P., Keatts H.C., and Menaker M. 1975c. On the role of eyes and brain photoreceptors in the sparrow: Entrainment to light cycles. J. Comp. Physiol. 102: 251.
Menaker M. 1968a. Extraretinal light perception in the sparrow. I. Entrainment of the biological clock. Proc. Natl. Acad. Sci. 59: 414 .

. 1968b. Light perception by extra-retinal receptors in the brain of the sparrow. In Proceedings of the 76th Annual Convention of the American Psychological Association, p. 299. American Psychological Association, Arlington, Virginia.

. 1971. Synchronization with the photic environment via extraretinal receptors in the avian brain. In Biochronometry: Proceedings of a Symposium (ed. M. Menaker), p. 314. National Academy of Sciences, Washington, D.C.

. 1977. Extraretinal photoreception. In The science of photobiology (ed. K.C. Smith), p. 227. Plenum, New York.

Menaker M. and Keatts H. 1968. Extraretinal light perception in the sparrow. II. Photoperiodic stimulation of testis growth. Proc. Natl. Acad. Sci. 60: 146.

Menaker M., Moreira L.F., and Tosini G. 1997. Evolution of circadian organization in vertebrates. Braz. J. Med. Biol. Res. 30: 305 .

Menaker M., Takahashi J.S., and Eskin A. 1978. The physiology of circadian pacemakers. Annu. Rev. Physiol. 40: 501.

Menaker M., Roberts R., Elliott J., and Underwood H. 1970. Extraretinal light perception in the sparrow. 3. The eyes do not participate in photoperiodic photoreception. Proc. Natl. Acad. Sci. 67: 320 .

Moore R.Y. and Lenn N.J. 1972. A retinohypothalamic projection in the rat. J. Comp. Neurol. 146: 1.

Morin L.P., Blanchard J.H., and Provencio I. 2003. Retinal ganglion cell projections to the hamster suprachiasmatic nucleus, intergeniculate leaflet, and visual midbrain: Bifurcation and melanopsin immunoreactivity. J. Comp. Neurol. 465: 401.

Morita Y., Tabata M., Uchida K., and Samejima M. 1992. Pineal-dependent locomotor activity of lamprey, Lampetra japonica, measured in relation to LD cycle and circadian rhythmicity. J. Comp. Physiol. A 171: 555.

Mrosovsky N. 2003. Aschoff's rule in retinally degenerate mice. J. Comp. Physiol. A 189: 75.

Nelson R.J. and Zucker I. 1981. Absence of extraocular photoreception in diurnal and nocturnal rodents exposed to direct sunlight. Comp. Biochem. Physiol. 69A: 145.

Panda S., Sato T.K., Castrucci A.M., Rollag M.D., DeGrip W.J., Hogenesch J.B., Provencio I., and Kay S.A. 2002. Melanopsin (Opn4) requirement for normal light-induced circadian phase shifting. Science 298: 2213

Panda S., Provencio I., Tu D.C., Pires S.S., Rollag M.D., Castrucci A.M., Pletcher M.T., Sato T.K., Wiltshire T., Andahazy M., Kay S.A., Van Gelder R.N., and Hogenesch J.B. 2003. Melanopsin is required for non-image-forming photic responses in blind mice. Science 301: 525.

Pasqualetti M., Bertolucci C., Ori M., Innocenti A., Magnone M.C., De Grip W.J., Nardi I., and Foa A. 2003. Identification of circadian brain photoreceptors mediating photic entrainment of behavioural rhythms in lizards. Eur. J. Neurosci. 18: 364.

Perez-Leon J.A., Warren E.J., Allen C.N., Robinson D.W., and Lane Brown R. 2006. Synaptic inputs to retinal ganglion cells that set the circadian clock. Eur. J. Neurosci. 24: 1117.

Plautz J.D., Kaneko M., Hall J.C., and Kay S.A. 1997. Independent photoreceptive circadian clocks throughout Drosophila. Science 278: 1632

Provencio I., Jiang G., De Grip W.J., Hayes W.P., and Rollag M.D. 1998. Melanopsin: An opsin in melanophores, brain, and eye. Proc. Natl. Acad. Sci. 95: 340.

Provencio I., Rodriguez I.R., Jiang G., Hayes W.P., Moreira E.F., and Rollag M.D. 2000. A novel human opsin in the inner retina. J. Neurosci. 20: 600

Ruby N.F., Brennan T.J., Xie X., Cao V., Franken P., Heller H.C., and O'Hara B.F. 2002. Role of melanopsin in circadian responses to light. Science 298: 2211.

Scharrer E. 1928. Die lichtempfindlichkeit blinder elritzen i. Untersuchungen uber das zwischenhirn der fische. $\mathrm{Z}$. $\mathrm{Vgl}$. Physiol. 7: 1 .

Seeliger M.W., Grimm C., Stahlberg F., Friedburg C., Jaissle G., Zrenner E., Guo H., Reme C.E., Humphries P., Hofmann F., Biel M., Fariss R.N., Redmond T.M., and Wenzel A. 2001. 
New views on Rpe65 deficiency: The rod system is the source of vision in a mouse model of Leber congenital amaurosis. Nat. Genet. 29: 70.

Shand J. and Foster R.G. 1999. The extraretinal photoreceptors of non-mammalian vertebrates. In Adaptive mechanisms in the ecology of vision (ed. S.N. Archer et al.), p. 197. Kluwer Academic, Dordrecht, The Netherlands.

Tomonari S., Takagi A., Noji S., and Ohuchi H. 2007. Expression pattern of the melanopsin-like (cOpn $4 \mathrm{~m})$ and VA opsin-like genes in the developing chicken retina and neural tissues. Gene Expr. Patterns (in press). AU: Update?

Torres G. and Lytle L.D. 1989. Extraretinal mechanisms mediate light-induced changes in neonatal rat pineal gland $\mathrm{N}$ acetyltransferase activity. J. Pineal Res. 7: 211.

Tosini G. and Menaker M. 1998. Multioscillatory circadian organization in a vertebrate, Iguana iguana. J. Neurosci. 18: 1105.

Tosini G., Doyle S., Geusz M., and Menaker M. 2000. Induction of photosensitivity in neonatal rat pineal gland. Proc. Natl. Acad. Sci. 97: 11540.

Underwood H. 1990. The pineal and melatonin: Regulators of circadian function in lower vertebrates. Experientia 46: 120.

Underwood H. and Menaker M. 1970. Photoperiodically significant photoreception in sparrows: Is the retina involved? Science 167: 298.

. 1976. Extraretinal photoreception in lizards. Photophysiology 23: 227.
Vigh B., Manzano M.J., Zadori A., Frank C.L., Lukats A., Rohlich P., Szel A., and David C. 2002. Nonvisual photoreceptors of the deep brain, pineal organs and retina. Histol. Histopathol. 17: 555.

Viney T.J., Balint K., Hillier D., Siegert S., Boldogkoi Z., Enquist L.W., Meister M., Cepko C.L., and Roska B. 2007. Local retinal circuits of melanopsin-containing ganglion cells identified by transsynaptic viral tracing. Curr. Biol. 17: 981.

von Frisch K. 1911. Beitrage zur physiologie der pigmentzellen inder fischhaut. Pflugers Arch. 138: 319.

Wenzel A., von Lintig J., Oberhauser V., Tanimoto N., Grimm C., and Seeliger M.W. 2007. Rpe65 is essential for the function of cone photoreceptors in nrl-deficient mice. Invest. Ophthalmol. Vis. Sci. 48: 534.

Whitmore D., Foulkes N.S., and Sassone-Corsi P. 2000. Light acts directly on organs and cells in culture to set the vertebrate circadian clock. Nature 404: 87.

Wong K.Y., Dunn F.A., Graham D.M., and Berson D.M. 2007. Synaptic influences on rat ganglion-cell photoreceptors. $J$. Physiol. 582: 279.

Zimmerman N.H. and Menaker M. 1979. The pineal gland: A pacemaker within the circadian system of the house sparrow. Proc. Natl. Acad. Sci. 76: 999.

Znoiko S.L., Rohrer B., Lu K., Lohr H.R., Crouch R.K., and Ma J.X. 2005. Downregulation of cone-specific gene expression and degeneration of cone photoreceptors in the rpe $65^{-1}$ mouse at early ages. Invest. Ophthalmol. Vis. Sci. 46: 1473. 


\section{$8_{\mathrm{CSH}}^{\infty} \mathrm{CH}$ Cold Spring Harbor Symposia SYMPOSIA}

\section{Circadian Photoreception in Vertebrates}

S. Doyle and M. Menaker

Cold Spring Harb Symp Quant Biol 2007 72: 499-508

Access the most recent version at doi:10.1101/sqb.2007.72.003

References This article cites 61 articles, 22 of which can be accessed free at: http://symposium.cshlp.org/content/72/499.full.html\#ref-list-1

\section{License}

Email Alerting

Receive free email alerts when new articles cite this article - sign up in the box at the Service top right corner of the article or click here.

To subscribe to Cold Spring Harbor Symposia on Quantitative Biology go to: http://symposium.cshlp.org/subscriptions 